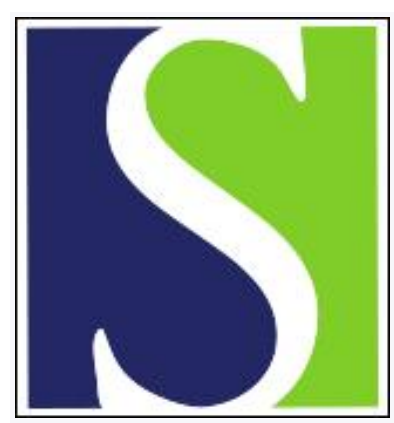

Scand J Work Environ Health 1983;9(2):194-200

https://doi.org/10.5271/sjweh.2426

Issue date: Apr 1983

Investigation of the after-reach hazard in two-hand controlled power press operations.

by Pizatella TJ, Etherton JR, Jensen RC, Oppold JA

This article in PubMed: www.ncbi.nlm.nih.gov/pubmed/6648417

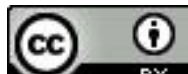




\title{
Investigation of the after-reach hazard in two-hand controlled power press operations
}

\author{
by Timothy J Pizatella, BSIE, John R Etherton, MEA, Roger C Jensen, MSE, \\ James A Oppold, PhD ${ }^{1}$
}

\begin{abstract}
PIZATELLA TJ, ETHERTON JR, JENSEN RC, OPFOLD JA. Investigation of the after-reach hazard in two-hand controlled power press operations. Scand $j$ work environ health 9 (1983) 194-200. One hazard inherent to hand-feeding operations at a power press occurs when a worker reaches into the point of operation after initiating the downward stroke of the press ram. One approach for controlling this hazard is to locate a two-hand actuator at a distance sufficiently far from the point of operation to prevent the operator from getting his hand into the die area before the ram completes its descent. In a study of this problem, the activities of a power press were simulated in the laboratory with the use of a model power press and two locations for the actuator controls, an upper and a lower location. The subjects performed simulated work cycles using the laboratory power press. Randomly an after-reach condition was created in which the subjects were to reach into the press die area to reposition a dislodged work blank. The after-reach time, ie, the time needed to reach from the actuator controls to the press die area, was measured. The results of this study indicated that there is a difference in hand-reach speed depending upon the location of the actuator controls. It was concluded that, to define hand-reach speed adequately, more research is needed to characterize the effect of other variables.
\end{abstract}

Key terms: actuator location, after-reach time, hand-reach speed, point of operation, simulated press, two-hand actuator.

There are approximately 2,000 amputations to press operators in the United States each year (5). One of the hazards which is inherent to hand-feeding operations at a power press and which contributes to these amputations is "afterreach." This hazard occurs when a worker suddenly reaches into the point of operation of a power press after initiating the downward stroke of the press ram. This out-of-sequence movement during the work cycle can result in the operator's hand being caught between the press ram and the dies.

There are safeguards which attempt to eliminate the after-reach hazard by

1 Division of Safety Research, National Institute for Occupational Safety and Health, Morgantown, West Virginia, United States.

Reprint requests to: $\mathrm{Mr}$ TJ Pizatella, National Institute for Occupational Safety and Health, 944 Chestnut Ridge Road, Morgantown, WV 26505, USA. occupying the hands in such a way that the time it takes the operator to reach into the point of operation is longer than the time it takes to eliminate the hazard. Hazard time is either the time needed to stop the downward motion of the ram or the time needed to close the pinch points. So long as the hazard time is less than the reach time, the operator will not be injured at the point of operation. One such method of protection is the use of two palm buttons requiring concurrent pressures to maintain machine motion. The release of either of the palm buttons causes the clutch to disengage and the brake to be applied to the press ram.

Reach time can be controlled with a minimum safety distance between the safety device (such as a two-hand actuator) and the point of operation if the speed of the reach movement is known. The traditionally accepted approach to setting a safety distance (D) is to base it 
on the hazard time ( $\mathrm{T}$ ) and a predetermined hand speed constant (S):

$$
\mathrm{D}(\mathrm{m})=\mathrm{S}(\mathrm{m} / \mathrm{s}) \times \mathrm{T}(\mathrm{s}) .
$$

Several problems exist with this approach. First, according to current US regulations, there is no specified method for measuring the safety distance as determined from the presented formula. Hence there is some confusion as to how the safety distance for locating the twohand controls should be measured. Because of the lack of a standard procedure for measuring the safety distance, differences in this distance can occur. If the safety distance is understated, press operators will not be adequately protected from the after-reach hazard because the safety distance will be too short and consequently allow the operator's hand to reach the point of operation before the hazard can be eliminated. Similarly, if the safety distance is overstated, then the hand will be traveling a greater distance than is required for adequate protection from the after-reach hazard, and a decrease in productivity will result. Therefore it is critical to safety, as well as productivity, that an accurate measure of distance be determined.

Secondly there is disagreement as to what value accurately represents the hand speed constant and whether this hand speed constant is adequate for use in safeguarding techniques other than twohand controls, eg, light curtains. Since the value used for hand speed has a direct effect on the safety distance to be used, it is important to the operator's safety that an accurate value be determined for the hand speed constant. Further problems arise in the determination of a hand speed constant because the after-reach time is not simply a function of reach time alone, but is thought to be a function of several variables. The location of the trip device, ie, two-hand actuators, in relationship to the point of operation is one important variable. The posture of the operator may create an interactive effect with the actuator location, while the pace of the regular task motions may also influence after-reach time. Other variables which could influence after-reach time include operator arm length and quickness, job task, and work environment.
A review of the literature revealed that several studies on the after-reach hazard have been conducted. A pioneering effort in this area was reported by IO Lobl in 1935 (3). Dr Lobl's experiments resulted in the decision by many standard setting organizations to use a hand speed constant of $1.6 \mathrm{~m} / \mathrm{s}$ as the basis of safety distance standards for power presses. Since this study was done, however, new questions have arisen concerning the comparability of Lobl's experimental model to actual workplace conditions and the equivalence of persons used in the study to the industrial population.

More recent studies have focused on defining human capabilities of pure motion and posture. They have primarily concentrated on the variables of worker quickness $(2,4)$ and posture (1). A study by Davies \& Mebarki (1) compared the difference in movement time in a horizontal forward motion of the hand from a standing and sitting posture. Van Ballegooijen (6) considered the danger of after-reach in the interaction between man and machine in metal working presses using two-hand controls. He compared the relationship between the operator's reach speed and the machine's stopping speed by photographically recording the performance of both. Operator speed for a straight-line reach movement of the hand was measured in a simulated experiment. A neon lamp was attached to the hand with an elastic band, and the hand path was photographically recorded with a strobe light. The actual stopping speed of a press ram was measured by attaching a light signal to the ram and photographically recording the impact stroke to determine the machine's stopping speed.

One limitation of these studies is that after-reach times were measured from the timing of a series of continuous reach movements which were unrelated to any task. This procedure may be unrealistic since it is not indicative of the after-reach condition occurring in the actual operation of power presses. Some of these studies suggest that nontask-related hand-reach speed may be in the range of 1.6 to 2.5 $\mathrm{m} / \mathrm{s}$. Obviously, if an inaccurate, slower hand speed is used for the calculation of the safe protective distance when the actual hand speed is greater, then the 
distance would be too close and therefore unsafe. To date, though, no study adequately defining task-related handreach speed has been published.

In addition, no study has considered after-reach in the context of actuator control location and work load. The purpose of the present study was to perform an investigation to determine if the location of two-hand acutator buttons has an effect on task-related hand-reach speed.

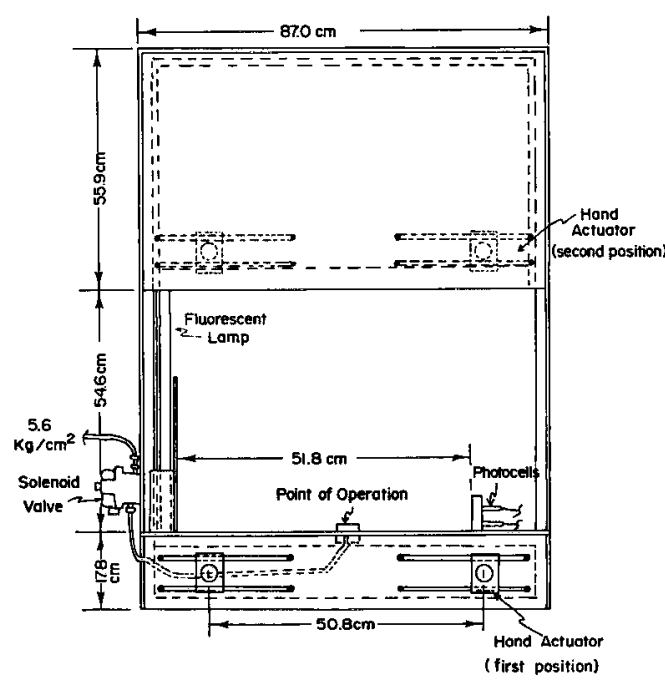

Fig 1. Sketch of the simulated power press. The two positions of the two-hand actuator controls are indicated.

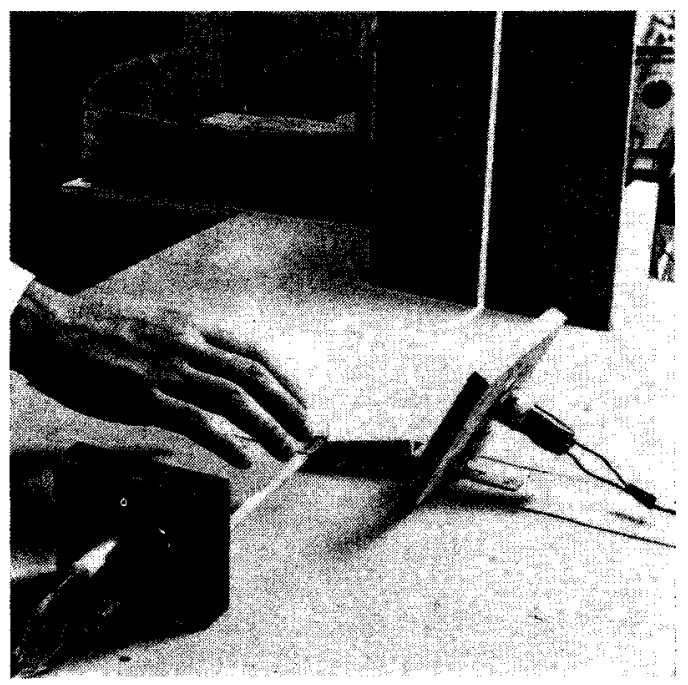

Fig 2. Photograph of a simulated after-reach movement showing the fingers interrupting the photo optical sensing plane.

\section{Methodology}

\section{Experimental apparatus}

In order to simulate the activities of press operators, a simulated press was developed. Initial ideas for the simulator were based on one constructed by Masters (4). The simulated press was placed on a table at a distance of $96.5 \mathrm{~cm}$ from the floor to the press bed. The simulator allowed for two different placements of the two-hand actuators. The first placement was $85.7 \mathrm{~cm}$ above the floor, $50.8 \mathrm{~cm}$ separating the centers of the actuator buttons (fig 1). This position is a common waist-high location for press operations. The second placement was $165.1 \mathrm{~cm}$ above the floor, $50.8 \mathrm{~cm}$ separating the centers (fig 1). Near the center of the press bed was a rectangular hole or "nest" which simulated a press die. Wooden blocks were used as workpieces. The press included a photo optical sensing plane which was produced by a fluorescent light, two photocells, and a plywood screen. The two photocells were mounted in a metal block and attached to the press bed opposite the fluorescent light. The plywood screen was used to align the photocells with the light, a photo optical sensing plane thus being created immediately in front of the nest (fig 2). The sensing plane was used to aid in the measurement of the after-reach time.

For simulation of the after-reach condition, pressurized air was used to displace the workpiece from the nest. An electric solenoid air valve was used to control pressurized air which entered the nest from an air line located underneath the press bed. When the air valve was opened, a pulse of air flowed through the line and displaced the workpiece from the nest, creating the after-reach condition. The subject, sensing this condition, was instructed to reach into the die area as quickly as possible to reposition the dislodged workpiece.

In order to start the timing interval, the actuator button contacts were electrically connected to a digital timer, which measured the time it took to move the hand from the actuator button to the point of operation. The timing device was activated when both the air valve was in the open position and the subject de- 
pressed both palm buttons. The timing interval terminated when the subject's fingers interrupted the photo optical sensing plane, automatically stopping the timer. The after-reach time was visually displayed on the timer located at the rear of the apparatus, not visible to the subject.

\section{Subjects}

Eight subjects were used in this study. All eight were male employees of the National Institute for Occupational Safety and Health in the 29- to 38-year age range. The mean age was 32.9 years. Seven of the subjects were normally right-handed, and one was normally lefthanded. None of the subjects had any prior experience operating a power press.

\section{Experimental procedure}

The subjects were given written procedures to read regarding the task they were to perform. Each subject received a training period during which he became familiar with the task and asked questions about the study. The task required the subject to move his right hand to a prepositioned tray on the right, grasp a "work blank" from the tray, and position it in the die at the "point of operation." The subject then brought both hands to the two-hand actuators and fully depressed both buttons, a procedure representing the activation of the press ram. With the left hand the subject removed the "completed workpiece" from the die and placed it in a prepositioned tray on the left. With a simultaneous movement of the right hand, the subject grasped another work blank from the right tray, positioned it in the die, and repeated the cycle. This procedure was followed to simulate as realistically as possible the routine work cycle in an actual power press operation without exposing subjects to the risks-associated with moving parts.

The experiment was performed with the actuator buttons in two different locations, upper and lower, as described earlier. Methods time measurement (MTM) was used to determine the normal cycle time for the task required in this study (approximately $5 \mathrm{~s} /$ work cycle or 12 work cycles/min). A light, which was set to flash once every $5 \mathrm{~s}$, was placed directly behind the nest area in the subject's direct view to help him maintain a consistent work rhythm throughout the study.

To minimize the effect of learning on the after-reach times, the subjects were placed in two groups of four persons; the groups were tested alternately, group I doing the lower location first and group II doing the upper location first.

The after-reach condition was created at random during the study and was controlled by the observer. A probability generator was used to aid the observer in determining the press cycles during which to activate the air valve and set-up the after-reach condition. This procedure was used to reduce the possibility of the subjects' anticipating which work cycles would require them to perform an afterreach movement. The air valve was activated with a switch located at the back of the press, where the observer was located and where it could not be seen by the subject. When the switch was closed, the valve would open, and pressurized air would flow through the air line and displace the workpiece at the instant the two actuator buttons were completely depressed. The subject, sensing an afterreach condition, was to move his hand (right or left) into the die area as quickly as possible and reposition the dislodged workpiece properly (fig 2). Each test session lasted approximately $30 \mathrm{~min}$.

\section{Variables}

The independent variables in this study were the two locations of the two-hand actuators and the eight subjects. Each subject performed 20 random after-reach movements at each actuator location, for a total of 160 observations per actuator location. The hand-reach speed ( $\mathrm{S}$ ) was determined from the measurement of the distance (d) from each actuator location to the press die area and the division of this distance by the observed after-reach times (t) for each subject:

$$
\mathrm{S}=\mathrm{d} / \mathrm{t} \text {. }
$$

This formula determines the average speed of moving the hand from an actuator button to the point of operation.

The distance from the lower actuator 
location to the die area was $55.4 \mathrm{~cm}$, and that from the upper actuator location to the die area was $85.6 \mathrm{~cm}$. The lower distance was determined as the sum of the distance from the center of a lower actuator button to the top of the press bed and the straight-line distance from that point to the die area. Similarly the upper distance was determined as the sum of the distance from the center of an upper actuator button to a point directly below the actuator where the hand has an unobstructed path to the die area and the straight-line distance from this point to the die area. This method appears to yield the best approximation of the path/distance that the hand actually travels in an afterreach movement without the hand path actually being measured.

\section{Results}

The overall mean average hand speed was $1.32 \mathrm{~m} / \mathrm{s}$ for the upper location and 0.94 $\mathrm{m} / \mathrm{s}$ for the lower location. The range of individual means was $1.08-1.66 \mathrm{~m} / \mathrm{s}$ for the upper location and $0.76-1.04 \mathrm{~m} / \mathrm{s}$ for the lower location. A histogram of this data is shown in fig 3 .

The data was evaluated with a two-way fixed effects analysis of variance model to determine if the variables, actuator location and subject, were significant in influencing hand-reach speed. The hypothesis was that the average hand-reach speed at the two actuator locations are equal. Table 1 is a summary of the analysis of variance that was performed on this data. From this analysis it was concluded that the interaction between the actuator location and the subject has a significant effect on average handreach speed.

\section{Discussion}

All the subjects exhibited a faster average hand-reach speed at the upper location than at the lower location. This is probably due to the different hand paths being traveled. The upper location allows for a relatively direct path between the actuator and the point or operation (die area). In addition the motion is with gravity. How-

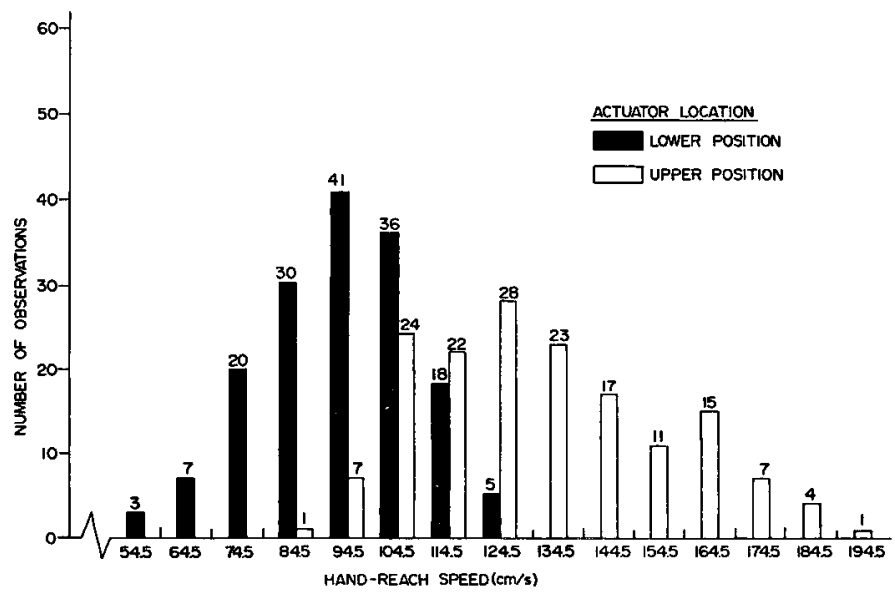

Fig 3. Plot of the hand speed data by actuator location.

Table 1. Summary of the analysis of variance.

\begin{tabular}{lcrrrr}
\hline Source & $\begin{array}{c}\text { Degrees of } \\
\text { freedom }\end{array}$ & $\begin{array}{c}\text { Sum of } \\
\text { squares }\end{array}$ & $\begin{array}{c}\text { Mean } \\
\text { square }\end{array}$ & F-value & $\begin{array}{c}\text { Probability } \\
>\mathrm{F}\end{array}$ \\
\hline Location & 1 & 12.01 & 12.01 & 1,201 & $<0.0001$ \\
Subject & 7 & 6.09 & 0.87 & 87 & $<0.0001$ \\
Location $\times$ subject & 7 & 1.90 & 0.27 & 27 & $<0001$ \\
Error & 304 & 4.50 & 0.01 & & \\
Total & 319 & 24.50 & & & \\
\hline
\end{tabular}


ever, the path associated with the lower location becomes multidirectional since the hand must move upward to clear the top of the press bed and then travel into the die area. Therefore more time was necessary to reach the danger point from this location. This result indicates that the path which the hand travels has an important bearing on how safety distances are set.

From fig 3 it can be seen that the hand speed values in the lower location were consistently less than $1.6 \mathrm{~m} / \mathrm{s}$, while in the upper location hand speed values for several of the subjects were greater than $1.6 \mathrm{~m} / \mathrm{s}$. Any safety distance calculated with the use of $1.6 \mathrm{~m} / \mathrm{s}$ would unsafely place the two-hand actuators too close to the point of operation when the hand speed was actually greater than $1.6 \mathrm{~m} / \mathrm{s}$. This finding identifies an important relationship between actuator location and hand-reach speed. It must be emphasized that these values are the result of a study using nonpress operators and that more research must be performed with a sample of actual press operators to evaluate operator hand speed more precisely.

A subjective comparison of the means of each group at each actuator location indicated that no significant learning effect occurred during the study. But, because subject and actuator location were not completely randomized within the experiment, there was no way to evaluate statistically any effect of learning on the hand-reach speed. It is recommended that future studies be designed to randomize the variables completely.

Several of the subjects experienced fatigue in the arms and back towards the end of the test session. Most of the subjects indicated that they experienced a greater degree of fatigue with the two-hand actuators in the upper location than in the lower location due to the need to continually raise the arms up to the actuator buttons for each work cycle.

One problem experienced with the solenoid valve was that the pulse of air flowing through the line created an initial "blast" that was distinctly audible. Although the subjects indicated that they could not effectively anticipate when they were to perform an after-reach movement, this sound may have become the signal to the subjects to perform the afterreach movement rather than the visual stimulus of the displaced workpiece from the die, which is a more realistic condition. Attempts were made to mask the sound by enclosing the valve in a box lined with acoustically absorbent material, but this procedure only reduced the noise and did not eliminate it completely. In future after-reach studies, a method of displacing the workpiece from the die needs to be developed which only stimulates the visual sense of the subjects.

\section{Conclusions}

This study was useful in developing a test apparatus and procedure that can be improved for future research efforts concerning the after-reach hazard. From this experiment we were able to determine that the combined effects of actuator location and individual variability has a significant effect on average hand-reach speed during a simulated power press operation. On the basis of the results of this study, it appears that standards for two-hand press operations based on a single-hand speed constant may be unnecessarily restrictive for some operations and not protective enough for others. A more appropriate method of setting safety distance based on actuator button location and type of work being performed should be investigated. It was also concluded that, to define hand-reach speed adequately, more research is needed. Specifically, future research efforts should be directed towards (i) characterizing the effect that other variables such as operator arm length, production rate, job task, and work environmental conditions have on hand-reach speed; (ii) testing the effect of these variables on subjects who are representative of the population of actual power press operators; (iii) comparing the results of these studies to current standards to determine if new standards are necessary; (iv) measuring the hand speed of press operators in a manner which would be appropriate for establishing safe distances for other safeguarding techniques such as light curtains; and (v) developing a standard procedure for measuring safety distance in the field. 


\section{Acknowledgment}

The authors would like to acknowledge the following individuals for their contributions to this research: $\mathrm{Mr} \mathrm{K}$ Bunting, $\mathrm{Mr} \mathrm{P}$ Hodson, $\mathrm{Mr} \mathrm{T}$ Hauge, $\mathrm{Ms} \mathrm{J} \mathrm{Ka-}$ zanowski, and Dr R Plummer.

\section{References}

1. Davies BT, Mebari B. Hand movement times and machine guarding. Ergonomics 24 (1981) $387-391$

2. Lievin D, Krawsky G, Mougeot B, Schouller JF. The security in a press operator system: A study of hand access to the danger zone. National Institute of Research and Security for the Prevention of Acciaents at Work and Job-Related Illnesses, Paris 1973.

3. Lobl IO. Concerning two hand trip on eccentric presses. Reichsarbeitsblatt (Berlin) (1935): 20 (part III), 150.

4. Masters RW. The location of two-hand trip devices on full revolution mechanical power presses with regard to operator safety. Master's thesis. Texas A \& M University, College Station, TX 1973.

5. McCaffrey DP. Work-related amputations by type and prevalence. Mon labor rev (1981) March 35-41.

6. Van Ballegooijen GA. Measurement on manmachine-systems under consideration of the repositioning risk. In: IVSS. Berufsgenossenschaft Nahrungsmittel und Gaststatten, Symposium, Heft 6 Mannheim, Federal Republic of Germany 1978, pp 79-89. (Paper no 5). 